\title{
Chemical recycling of poly(ethylene terephthalate). Application to the synthesis of multiblock copolyesters
}

\author{
A. El Mejjatti ${ }^{1}$, T. Harit ${ }^{1}$, A. Riahi ${ }^{2}$, R. Khiari ${ }^{3}$, I. Bouabdallah $^{1}$, F. Malek $^{1 *}$ \\ ${ }^{1}$ Laboratoire de Chimie Organique, Macromoléculaire et Produits Naturels - URAC 25 Faculté des Sciences - Université \\ Mohamed Premier. Bd Mohamed VI, BP : 717 - 60000 Oujda - Maroc \\ ${ }^{2}$ Université de Reims Champagne-Ardenne, Institut de Chimie Moléculaire de Reims (ICMR)- Groupe Méthodologie en \\ Synthèse Organique, CNRS UMR 6229, Bat. Europol'Agro-Moulin de la Housse, BP 1039, 51687 Reims Cedex 2, \\ France \\ ${ }^{3}$ Laboratoire de Chimie Appliquée et Environnement, Faculté des Sciences - Université de Monastir, 5000 Tunisie
}

Received 29 January 2014; accepted in revised form 2 April 2014

\begin{abstract}
The chemical recycling of the poly(ethylene terephthalate), (PET), has been successfully carried out by glycolysis in the presence of bis (2-hydroxyethyl) terephthalate (BHET) resulting in the formation of hydroxytelechelic oligomers. These oligomers were then treated with carboxytelechelic poly( $\varepsilon$-caprolactone) oligomers of $\bar{M}_{\mathrm{n}}=2300$ and $\bar{M}_{\mathrm{n}}=$ $730 \mathrm{~g} \cdot \mathrm{mol}^{-1}$ molecular weight, in the absence or presence of the titanium tetrabutyloxide $\left(\mathrm{Ti}(\mathrm{OBu})_{4}\right)$ as a catalyst to get multiblock copolyesters. The chemical structure of the synthesized copolyesters was investigated by size exclusion chromatography (SEC) and proton Nuclear Magnetic Resonance $\left({ }^{1} \mathrm{H}\right.$ NMR) spectroscopy. Moreover the differential scanning calorimetry (DSC) was used to explore their thermal properties. The ester-ester interchange reaction was observed between the two oligopolyesters, was studied and discussed in detail.
\end{abstract}

Keywords: recycling, poly(ethylene terephthalate), polyesterification, thermal analysis

\section{Introduction}

Poly(ethylene terephthalate), (PET), is a thermoplastic semi-crystalline polyester with excellent tensile and impact strength, chemical resistance, clarity, process ability, transparency, and appropriate thermal stability [1]. It is mainly used in the textile industry, to manufacture of video and audio tapes, X-ray films, food packaging, water and soft-drink bottles. The global consumption of PET packaging was almost 15.5 Mt in 2009, while it is expected to reach 19.1 Mt by 2017 , a $5.2 \%$ increase per annum $[2,3]$. The increased consumption of PET is creating serious environmental problems as vast waste stream reaches every year due to short life duration of PET etc. Disposing of the waste to the landfill is becoming undesirable due to legislation pressures, rising costs and the poor biodegradability of such polymers. Therefore, other ways of PET waste treatment, such as recycling is highly desired.

Polymer wastes can be recycled in many ways for example, the energetic valorization which consists of using energy emanating from PET burning. Another method called mechanical recycling where the polymers are transformed into other objects after a step in the molten state. The recycled PET is used in different applications which do not require very high quality standards $[4,5]$. Among all polymer recycling methods, chemical method has attracted more attention due to sustainable development principles. This method is very useful for the condensation of polymers, such as polyamides, polyurethanes and polyesters, which are vulnerable to solvolytic chain

\footnotetext{
*Corresponding author, e-mail: fouad malek@yahoo.fr

(C) BME-PT
} 
cleavage. The key advantage of this method includes the huge availability of the different chemical products which can be obtained with different reagents [6-9].

Recently, several processes such as alcoholysis, aminolysis, hydrolysis, and glycolysis have been used for PET chemical recycling. Glycolysis reaction is more interesting, and can be described as a molecular depolymerisation by transesterification between PET ester groups and a diol. The ester linkages are therefore broken and replaced with hydroxyl terminals. The monomers or higher oligomers obtained can be used as building blocks to synthesize other polymers with higher economical values. For example, saturated and unsaturated polyesters [10-12], polyurethanes [13-15], coating materials [16-19] and additives [20-22] have been synthesized from such building blocks in recent years.

A large number of reagents have been used for glycolysis of PET such as ethylene glycol [23-26], diethylene glycol [27, 28], propylene glycol [29], neopentyl glycol [14], 1,4-butanediol [30, 31], and some synthetic oligoesters $[32,33]$. To the best of our knowledge, no one has ever been used BHET as diol for the PET glycolysis. Similarly, several studies have been carried out on the reaction of PET and ethylene glycol for the synthesis of hydroxytelechelic oligomers of PET [34-36] which were mainly used for producing unsatured polyester resins [34, 35] and very few polycondensations have been carried out by using hydroxytelechelic oligomers of PET with $\varepsilon$-caprolactone [37]. Copolyesters with PET and $\varepsilon$-caprolactone units are mainly synthesized by polycondensation of dimethyl terephthalate, ethylene glycol and $\varepsilon$-caprolactone [38], or by transesterification in copolyester blend $[39,40]$.

In this context, in order to explore a new method for PET recycling herein, the glycolysis of the PET performed with its structural units BHET was reported. This paper presents a continuous reactive extrusion process and evaluates the potentiality of the polyesterification of hydroxytelechelic oligomers resulting from the glycolysis of PET with the carboxytelechelic PCL oligomers as a new method for valorization of PET wastes. All the obtained products are investigated by proton nuclear magnetic resonance spectroscopy ( ${ }^{1} \mathrm{H}$ NMR), size exclusion chromatography (SEC) and differential scanning calorimetry (DSC).

\section{Experimental part}

\subsection{Reagents}

Poly(ethylene terephtalate) (PET) $\left(\bar{M}_{\mathrm{n}}=\right.$ $\left.26000 \mathrm{~g} \cdot \mathrm{mol}^{-1}\right)$, bis(2-hydroxyethyl) terephthalate (BHET), poly ( $\varepsilon$-caprolactone) diol (PCL) $\left(\bar{M}_{\mathrm{n}}=\right.$ 530 and $\left.2000 \mathrm{~g} \cdot \mathrm{mol}^{-1}\right)$, zinc acetate $\left(\mathrm{Ac}_{2} \mathrm{Zn}\right)$, and titanium tetrabutyl oxide $(\mathrm{Ti}(\mathrm{OBu}) 4)$, are obtained from Sigma-Aldrich ( St Quentin Fallavier, France). All other chemicals (solvents and reagents) were used of analytical grade and were obtained from Somaprol (Casablanca, Morocco).

\subsection{Glycolysis of PET by BHET}

PET pellets (20.03 g; $0.104 \mathrm{~mol}$ (PET monomer unit)), BHET (26.50 g; $0.208 \mathrm{~mol}$ of hydroxyl equivalent), and $0.20 \mathrm{~g}$ of zinc acetate $\left(\mathrm{Ac}_{2} \mathrm{Zn}\right)$ were put into a $500 \mathrm{~mL}$ reactor equipped with a mechanic stirrer, a nitrogen inlet and a vacuum outlet. The reactor was heated under nitrogen at $250^{\circ} \mathrm{C}$ for $2 \mathrm{~h}$. After the die, the modified PET crystallized in bulk and it is grinded into powder, and the residual BHET is removed by precipitation in hot water. The white product was dried under a vacuum at $80^{\circ} \mathrm{C}$ for $48 \mathrm{~h}$. The powder was obtained in an $85 \%$ yield and characterized by ${ }^{1} \mathrm{H}$ NMR spectroscopy with trifluoroacetic acid (TFA) and Deuterated chloroform $\left(\mathrm{CDCl}_{3}\right)$ as the solvent.

${ }^{1} \mathrm{H}$ NMR: $\delta$ (ppm): 8.10 (aromatic protons) $4.70\left(\mathrm{C}_{2}\right.$ between two esters functions); $4.55\left(\mathrm{C}_{2} \mathrm{CH}_{2} \mathrm{OH}\right)$; $4,15\left(\mathrm{C}_{2} \mathrm{OH}\right)$.

\subsection{Synthesis of carboxytelechelic poly(E-caprolactone) oligomers}

The carboxytelechelic poly( $\varepsilon$-caprolactone) oligomers of molecular weight $\bar{M}_{\mathrm{n}}=2300 \mathrm{~g} \cdot \mathrm{mol}^{-1}$ and $\bar{M}_{\mathrm{n}}=730 \mathrm{~g} \cdot \mathrm{mol}^{-1}$ are prepared from hydroxytelechelic oligomers of molecular weight 2000 and $530 \mathrm{~g} \cdot \mathrm{mol}^{-1}$ respectively, according to the procedure described in the literature [41].

In a $500 \mathrm{~mL}$ two-necked flask equipped with a condenser, a nitrogen inlet and a magnetic stirrer, $20 \mathrm{~g}$ $(0.01 \mathrm{~mol})$ of PCL, $2.2 \mathrm{~g}(0.022 \mathrm{~mol})$ of succinic anhydride and $1 \mathrm{~mol} \%$ of DMAP with $200 \mathrm{~mL}$ of 1,4-dioxan solvent were introduced. The reaction has occurred at $50^{\circ} \mathrm{C}$. After 10 hours of reaction, the solvent was removed by evaporation under vacuum at $100^{\circ} \mathrm{C}$ and the residual product was solubilized in chloroform. The reaction mixture was washed with acidic water $(\mathrm{pH}=1)$ in order to remove residual suc- 
cinic acid. After drying on $\mathrm{Na}_{2} \mathrm{SO}_{4}$, the solvent was removed by evaporation and under vacuum at $60^{\circ} \mathrm{C}$. The mass yield of the reaction was $80 \%$. The products are characterized by $\mathrm{pH}$ titration of carboxylic functions, ${ }^{1} \mathrm{H}$ NMR spectroscopy and SEC.

The titration of carboxylic functions of the products (of the addition of succinic acid onto hydroxyl function) is carried out by following a classic method: a known mass of the product is titrated by a solution of $\mathrm{KOH}$ in methanol $(\mathrm{MeOH})$ solvent with tetrahydrofuran (THF) as solvent and phenolphthalein as color indicator. The carboxyl ratio is given by the Equation (1):

$I_{\mathrm{COOH}}=\frac{C_{\mathrm{KOH}} \cdot V_{\mathrm{KOH}}}{m}$

where $C_{\mathrm{KOH}}$ represents the concentration of $\mathrm{KOH}$ solution, $V_{\mathrm{KOH}}$ is the equivalent volume and $m$ is the mass of oligomer titrated. These tests were performed at least in duplicate, and the difference between the various obtained values was within the experimental error of $5 \%$.

${ }^{1} \mathrm{H}$ NMR: $\delta$ (ppm): 8.4 (acid proton); $4.1\left(\mathrm{CH}_{2}\right.$ between two ester functions, one linked to caprolactone unit (in $\alpha$ ) and one linked to succinic unit (in $\beta)) ; 4.0\left(\mathrm{CH}_{2}\right.$ of caprolactone unit in $\alpha$ of ester function); $3.6\left(\mathrm{CH}_{2}\right.$ between two ester functions, one linked to caprolactone unit (in $\beta$ ) and another linked to succinic unit (in $\alpha)) ; 2.6\left(\mathrm{CH}_{2}\right.$ between an ester and a carboxylic function); $2.3\left(\mathrm{CH}_{2}\right.$ in $\alpha$ of a carboxyl group and methylenic carbon); $1.1-1.7$ (Internal $\mathrm{CH}_{2}$ of caprolactone unit).

\subsection{Copolyesterification of hydroxytelechelic PET oligomers and carboxytelechelic poly(e-caprolactone) oligomers}

The reaction of copolyesterification of carboxytelechelic oligomers with hydroxytelechelic oligomers of PET is performed in a bulk, in a four-necked flask, with a condenser, a nitrogen inlet, a mechanical stirrer and a high vacuum inlet.

The hydroxytelechelic PET oligomers, the carboxytelechelic poly( $\varepsilon$-caprolactone) oligomers $\left(\bar{M}_{\mathrm{n}}=730\right.$ or $\left.2300 \mathrm{~g} \cdot \mathrm{mol}^{-1}\right)$ and $1 \mathrm{wt} \%$ of catalyst $\left(\mathrm{Ti}(\mathrm{OBu})_{4}\right)$ (or without catalyst) are introduced and the reaction mixer is heated at $240^{\circ} \mathrm{C}$ under nitrogen until the complete fusion of oligomers of PET. After, the pressure is led to $10^{-1}$ mbar in the reactor and the reaction temperature is kept constant at $240^{\circ} \mathrm{C}$. The copolyesters are obtained with yield ranging from 85 to $90 \%$. Subsequently the products are characterized by SEC, ${ }^{1} \mathrm{H}$ NMR as well by DSC.

${ }^{1} \mathrm{H}$ NMR: $\delta$ (ppm) 8.1 (aromatic protons); $4.2\left(\mathrm{CH}_{2}\right.$ between two ester functions, one linked to caprolactone unit (in $\alpha$ ) and another linked to succinic unit (in $\beta)) ; 4.0\left(\mathrm{CH}_{2}\right.$ of caprolactone unit in $\alpha$ of ester function); $3.6\left(\mathrm{CH}_{2}\right.$ between two ester functions, one linked to caprolactone unit (in $\beta$ ) and one linked to succinic unit (in $\alpha)$ ); $2.65\left(\mathrm{CH}_{2}\right.$ between an ester and a carboxylic function); $2.3\left(\mathrm{CH}_{2}\right.$ in $\alpha$ of a carboxyl group and methylenic carbon) ; 1.0-1.7 (internal $\mathrm{CH}_{2}$ of caprolactone unit).

\subsection{Apparatus}

\subsubsection{Nuclear magnetic resonance (NMR)}

The ${ }^{1} \mathrm{H}$ NMR spectra are recorded on a Bruker spectrometer $250 \mathrm{MHz}$ at room temperature. The solvent used for oligomers of PET is $\mathrm{CDCl}_{3} / \mathrm{TFA}(20: 1)$. The solvent for the other products is $\mathrm{CDCl}_{3}$. Chemical shifts are given in ppm relative to Tetramethylsilane as an internal reference.

\subsubsection{Size exclusion chromatography (SEC)}

The size exclusion chromatograms are recorded on an IOTA2 apparatus supplied by JASCO with a PU980 Intelligent HPLC pump. The columns employed were PLgel $5 \mu \mathrm{m}$ Mixed-D $300 \times 7.5 \mathrm{~mm}$, VARIAN INC. The molecular weights of poly ( $\varepsilon$-caprolactone) oligomers and of copolyesters are measured respectively with THF or chloroform/ hexafluoropropan2-ol $\left(\mathrm{CHCl}_{3} / \mathrm{HFIP}\right)(98 / 2 \mathrm{wt})$ as solvent at a flow rate of $1 \mathrm{~mL} \cdot \mathrm{min}^{-1}$. Samples are injected using an injector of the Agilent 100 Series. The calibration curves are obtained from polystyrene (PS) standards. These tests were performed at least in duplicate, and the difference between the various obtained values was within the experimental error of $5 \%$.

\subsubsection{Differential scanning calorimetry (DSC)}

DSC analyses were performed with a 204 F1 NET$\mathrm{ZSCH}$. Experiments are carried out under nitrogen with samples ranging from 7 to $15 \mathrm{mg}$. The temperature was calibrated with ultra-pure indium, octane and dodecyloctane. The temperature range of the first heating scan was between -80 to $280^{\circ} \mathrm{C}$, with a heating rate of $10 \mathrm{~K} \cdot \mathrm{min}^{-1}$, followed by a cooling at $20 \mathrm{~K} \cdot \mathrm{min}^{-1}$. A second scan was immediately performed with a heating rate of $10 \mathrm{~K} \cdot \mathrm{min}^{-1}$. Glass tran- 
sition temperature was taken at the midpoint of change in heat capacity. These measurements were performed at least in duplicate.

\section{Results and discussion \\ 3.1. Synthesis of PET oligomers}

The synthesis of hydroxytelechelic oligomers of PET was performed by glycolysis of PET with its monomer BHET using zinc acetate $\left(\mathrm{Ac}_{2} \mathrm{Zn}\right)$ as the catalyst. This reaction of depolymerization is described in Figure 1.

As described in several previous studies [32, 35, $36]$ the PET glycolysis products are $\alpha, \omega$-hydroxyl oligomers. Indeed, different SEC analysis, ${ }^{1} \mathrm{H}$ NMR spectroscopy, and matrix-assisted laser desorption ionization time-of-flight mass spectrometry was established; these studies show a good correlation in the determination of hydroxyl end groups and molecular weights below $4000 \mathrm{~g} \cdot \mathrm{mol}^{-1}$.

The four peaks of the ${ }^{1} \mathrm{H}$ NMR spectrum as reported in Figure 2, correspond to the signals of PET oligomer protons. The average molecular weight of the oligomers is calculated from ${ }^{1} \mathrm{H}$ NMR spectroscopy using the integrations of the aromatic protons and the methylene protons adjacent to the hydroxyl end functions. The integration ratio of these signals allowed the calculation of the number of terephthalic base units in the oligomers through Equation (2):

$m=\frac{I_{8.10 \mathrm{ppm}}}{I_{4.15 \mathrm{ppm}}}$

where $I_{\mathrm{x} \text { ppm }}$ represents the integral value of the peak centered at $x$ ppm.

So it is easy to determine the average molecular weight of the oligomers. The $\mathrm{m}$ value is about $100 / 14.7=6.8$. The PET oligomer has an average

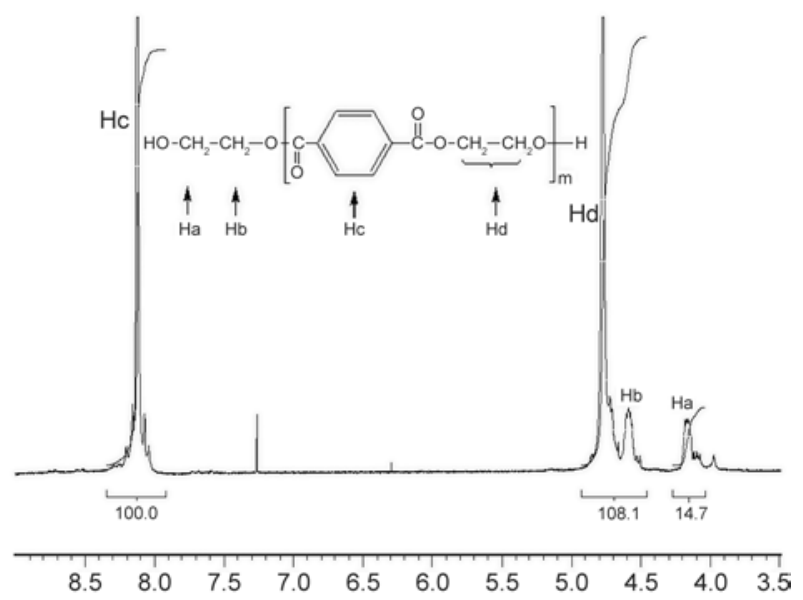

Figure 2. ${ }^{1} \mathrm{H}$ NMR spectrum of hydroxytelechelic oligomers of PET

molecular mass of $1360 \mathrm{~g} \cdot \mathrm{mol}^{-1}$, with an average polymerization number $\left(\overline{\mathrm{DP}}_{\mathrm{n}}\right)$ of 13.6.

In these conditions, the molar weight of the obtained glycosilation products were lower than the products reported in the literature (about $1450 \mathrm{~g} \cdot \mathrm{mol}^{-1}$ [35] and $\left.1800 \mathrm{~g} \cdot \mathrm{mol}^{-1}[36]\right)$, these values were obtained during the PET glycolysis with the ethylene glycol, using dibutyl tin oxide as the catalyst.

The PET oligomer is soluble only in few solvents, for this reason, it is used in the molten state for further polyaddition. The differential scanning calorimetry (DSC) analysis gives the glass transition temperature $\left(T_{\mathrm{g}}=78^{\circ} \mathrm{C}\right)$, melting point $\left(T_{\mathrm{m}}=235^{\circ} \mathrm{C}\right)$ and crystallization temperature $\left(T_{\mathrm{c}}=175^{\circ} \mathrm{C}\right)$ of the glycolysed PET oligomers.

The product has a melting temperature close to that of PET, but slightly lower. This is in good agreement with the literature data $[5,35]$, which shows that the melting temperature depends on and varies from 110 up to $220^{\circ} \mathrm{C}$ when $\overline{\mathrm{DP}}_{\mathrm{n}}$ varies from one to five. For $\overline{\mathrm{DP}}_{\mathrm{n}}$ above five, the melting temperature is very close to that of PET.

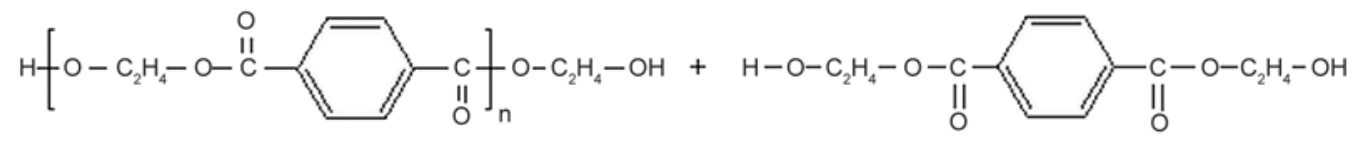<smiles>CC(C)OC=COC(=O)c1ccc(C(=O)C(C)(C)C)cc1</smiles>

where $m<<n$

Figure 1. Depolymerization of PET by BHET 


\subsection{Synthesis of carboxytelechelic of poly(e-caprolactone) oligomers}

The carboxytelechelic PCL oligomers are not commercially available.Their synthesis was performed by reacting succinic anhydride with the hydroxyl functions of the commercial PCL oligomers using dimethylaminopyridine (DMAP) as a catalyst, as shown in Figure 3.

The synthesis and characterization of the carboxytelechelic poly( $\varepsilon$-caprolactone) oligomers of molecular weight $\bar{M}_{\mathrm{n}}=2300 \mathrm{~g} \cdot \mathrm{mol}^{-1}$ and $\bar{M}_{\mathrm{n}}=730 \mathrm{~g} \cdot \mathrm{mol}^{-1}$ from hydroxytelechelic oligomers of molecular weight 2000 and $530 \mathrm{~g} \cdot \mathrm{mol}^{-1}$ respectively [41] has been described. The structure of these oligomers is confirmed by ${ }^{1} \mathrm{H} \mathrm{NMR}, \mathrm{pH}$ titration of carboxylic functions and size exclusion chromatography. In their ${ }^{1} \mathrm{H}$ NMR spectra, it can be noticed that the presence of a broad signal at $8.4 \mathrm{ppm}$ corresponding to the acid proton. The $\alpha$ - and $\beta$-protons of the acid function appears as a multiplet centred at $2.6 \mathrm{ppm}$. Other peaks correspond to the protons of the aliphatic chain of PCL. The peak integration ratios of different signals confirmed clearly the esterification reaction between the succinic anhydride and the PCL diol. The titration of the carboxyl functions allowed us the calculation of the carboxylic functionality of PCL, which has been determined to be 1.98 in both cases, as described in the experimental part.

\subsection{Synthesis and characterization of copolyesters}

The copolyesterification of hydroxytelechelic PET oligomers and carboxytelechelic PCL oligomers was performed in the molten state, under vacuum $\left(10^{-1} \mathrm{mbar}\right)$ and high temperature so as to get rid of water formed, to shift the esterification equilibrium. The reaction is performed at $240^{\circ} \mathrm{C}$ because of the high melting point of PET oligomers, using $\mathrm{Ti}(\mathrm{OBu})_{4}$ as a catalyst, as shown in Figure 4.

As reported in the literature, the $\mathrm{Ti}(\mathrm{OBu})_{4}$ is more reactive when being used at a reaction temperature of $240^{\circ} \mathrm{C}$ and enhances somewhat the $\bar{M}_{\mathrm{n}}$ obtained [42]. For titanium catalytic system, studied by Fradet and Marechal [43], the acid function coordinates with $\mathrm{Ti}$, and some experiments of Fradet and Marechal show that the system follows thermodynamic laws. Indeed, the rate constant of the reaction increases with increasing of the temperature. Other works enlighten the same phenomenon and give further explanations onto titanium alkoxide activity for esterification or transesterification reactions [42, 44].

To study the influence of the molecular weight of PCL carboxytelechelic on the properties of co-polyesters, the polyesterification reactions were established with the PCL oligomers of $\bar{M}_{\mathrm{n}}=2300 \mathrm{~g} \cdot \mathrm{mol}^{-1}$ and $\bar{M}_{\mathrm{n}}=730 \mathrm{~g} \cdot \mathrm{mol}^{-1}$. In the same way, in order to evaluate the influence of the catalyst on these prop-

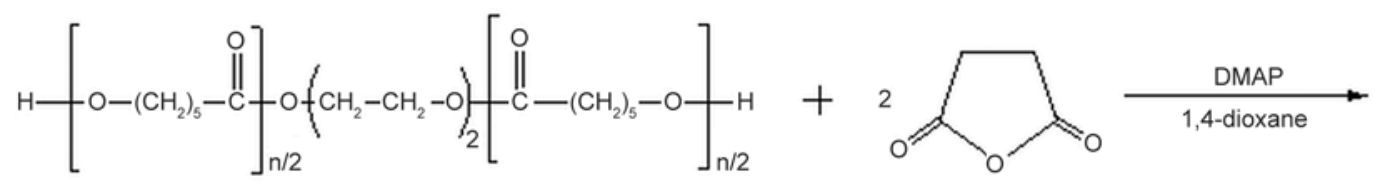

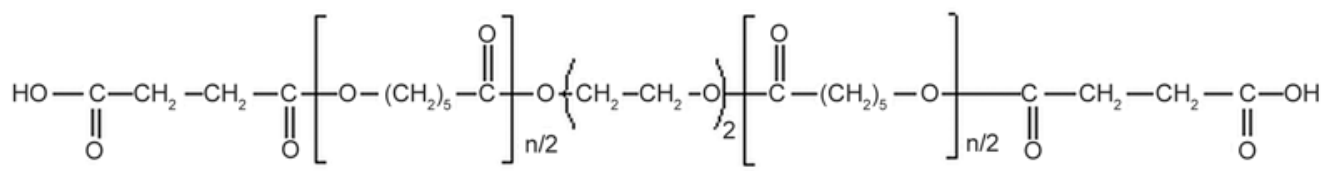

Figure 3. Synthesis of carboxytelechelic PCL oligomers

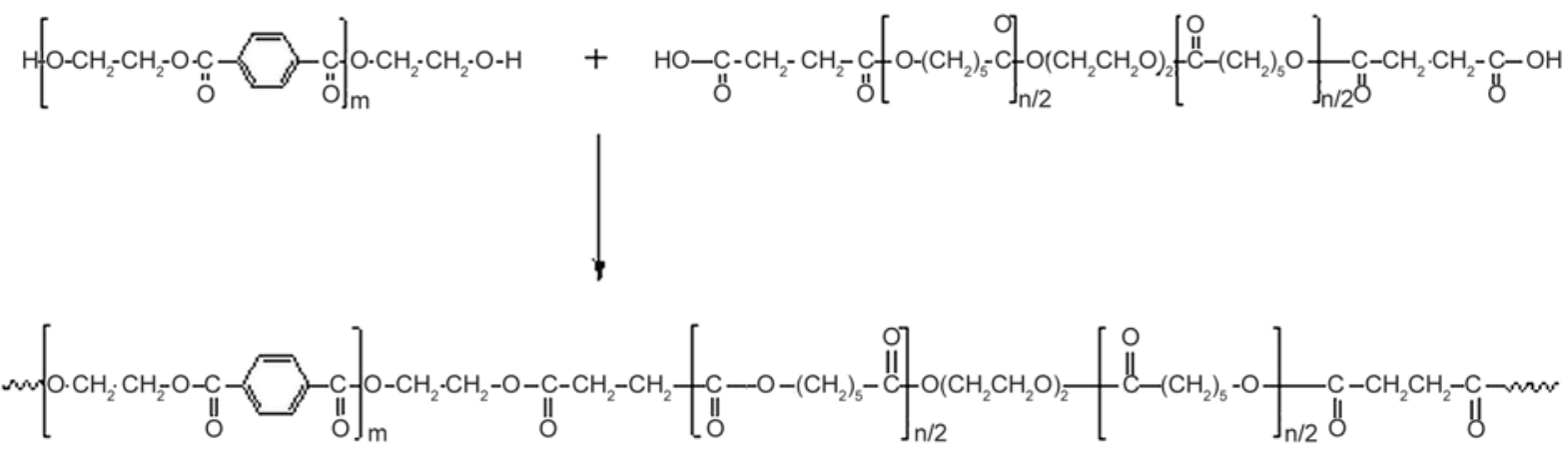

Figure 4. Copolyesterification of hydroxytelechelic PET oligomers and carboxytelechelic PCL oligomers 
Table 1. Properties of products of copolyesterification

\begin{tabular}{|c|c|c|c|c|c|c|c|c|c|}
\hline Copolyester & $\begin{array}{c}\text { PET } \\
{[g]}\end{array}$ & $\begin{array}{c}\text { PCL } \\
{[\mathrm{g}]}\end{array}$ & $\begin{array}{c}\mathrm{Ti}(\mathrm{OBu})_{4} \\
{[\mathrm{wt} \%]}\end{array}$ & $\begin{array}{c}\overline{\mathbf{M}}_{\mathrm{n}} \\
{\left[\mathrm{g} \cdot \mathrm{mol}^{-1}\right]^{\mathrm{c}}}\end{array}$ & $\begin{array}{c}\overline{\mathbf{M}}_{\mathrm{w}} \\
{\left[\mathrm{g} \cdot \mathrm{mol}^{-1}\right]^{\mathrm{c}}}\end{array}$ & $\mathbf{I}_{\mathbf{p}}{ }^{\mathbf{c}}$ & $\begin{array}{l}\mathbf{T}_{\mathbf{g}}{ }^{\mathrm{d}} \\
{\left[{ }^{0} \mathbf{C}\right]}\end{array}$ & $\begin{array}{l}\mathbf{T}_{\mathbf{m}}{ }^{\mathrm{d}} \\
{\left[{ }^{\circ} \mathbf{C}\right]}\end{array}$ & $\begin{array}{c}\text { Ester-ester reaction } \\
{[\%]^{\mathrm{e}}}\end{array}$ \\
\hline$\underline{1}$ & 25 & $40^{\mathrm{a}}$ & 1 & 21000 & 38800 & 1.85 & -20 & - & 35 \\
\hline$\underline{2}$ & 25 & $13^{\mathrm{b}}$ & 1 & 22500 & 38200 & 1.70 & -10 & 200 & 15 \\
\hline$\underline{\mathbf{3}}$ & 25 & $13^{\mathrm{b}}$ & 0 & 19500 & 37000 & 1.90 & -6 & 208 & 8 \\
\hline
\end{tabular}

${ }^{\mathrm{a}}$ Experiments led by using carboxytelechelic poly( $\varepsilon$-caprolactone) oligomers with molecular weight of $2300 \mathrm{~g} \cdot \mathrm{mol}^{-1}$.

${ }^{\mathrm{b}}$ Experiments led by using carboxytelechelic poly( $\varepsilon$-caprolactone) oligomers of molecular weight of $730 \mathrm{~g} \cdot \mathrm{mol}^{-1}$.

${ }^{c}$ Determined by size exclusion chromatography in $\mathrm{CHCl}_{3} / \mathrm{HFIP}(98 / 2 \mathrm{wt})$ with monodisperse PS standards

${ }^{\mathrm{d}}$ Determined by DSC at $20^{\circ} \mathrm{C} \cdot \mathrm{min}^{-1}$.

${ }^{\mathrm{e}}$ Determined by ${ }^{1} \mathrm{H}$ NMR spectroscopy.

erties, an uncatalyzed reaction with the oligomers of $\bar{M}_{\mathrm{n}}=730 \mathrm{~g} \cdot \mathrm{mol}^{-1}$ was accomplished. All the characterization results of the obtained copolyesters are reported in Table 1.

The molecular weights of the obtained copolyesters are comprised between 19500 and $22500 \mathrm{~g} \cdot \mathrm{mol}^{-1}$ and the polydispersity index is close to 2 . This value is characteristic for the polycondensation reactions. The molecular weight of the copolyester $\underline{\mathbf{1}}$ is lower than the copolyester $\underline{\mathbf{2}}$. This can be easily explained by the lower reactivity of terminal carboxylic functions of the high molecular weights oligomers as well as by the steric environment, which prevents hydroxyl functions of PET oligomers to reacting with the carboxylic functions. It can be also noticed that the uncatalyzed reaction gives molar mass polyester (copolyester $\underline{\mathbf{3}}$ ) slightly lower. The obtained result is in good agreement with the literature [42, 43].

The ${ }^{1} \mathrm{H}$ NMR spectrum of polyesterification products (Figure 5) showed the main conventional spectroscopic fingerprints of PET and PCL blocks, respectively, and the chemical linkage between the different blocks.

From the spectra, some signals coming from esterester interchange reaction between base monomers units are represented in Table 2. The ester-ester exchange reaction is a well-known phenomenon that occurs in a polyester chain [45-47]. This reaction comes from internal trans-esterification reactions, leading to inversion of monomers base units into the polyester chain. Their study focused on the

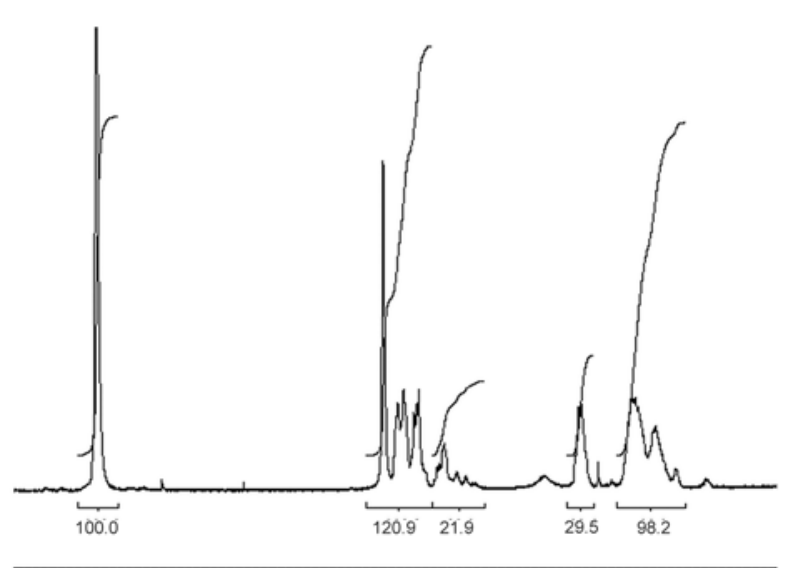

9.08 .58 .07 .57 .06 .56 .05 .55 .04 .54 .03 .53 .02 .52 .01 .51 .00 .5

Figure 5. ${ }^{1} \mathrm{H}$ NMR spectroscopy of copolyesters

polymers blends, but not on a chemical reaction between PET oligomers and the PCL.

The ${ }^{1} \mathrm{H}$ NMR spectroscopy allows then the calculation of the percentage of ester-ester interchange reaction. This side reaction rate can be determined by using the value of the integration of the peaks at 4.6 and $8.0 \mathrm{ppm}$ (named respectively, $I_{4.6}$ and $I_{8.0}$ ). If the trans-esterification reaction had not occurred, the ratio I4.6/I8 would not have been modified between the spectrum of oligomers of PET and the copolyesters. The percentage of transesterification phenomenon can be easily determined when comparing the ratio of the integration of the signals at 8 and $4.6 \mathrm{ppm}$ of the PET precursor oligomers and the one of the copolyester. As a result the percentage of transesterification is given by the Equation (3): $\%$ transesterification $=\left[1-\frac{\left(\frac{I_{4.6 \mathrm{ppm}}}{I_{8.0 \mathrm{ppm}}}\right) \text { in copolyester }}{\left(\frac{I_{4.6 \mathrm{ppm}}}{I_{8.0 \mathrm{ppm}}}\right) \text { in PET oligomer }}\right]$ 
Table 2. ${ }^{1} \mathrm{H}$ NMR study of transesterification products

\begin{tabular}{|c|c|c|}
\hline $\begin{array}{c}\text { Chemical shift } \\
{[\mathrm{ppm}]}\end{array}$ & Coming from & Chemical structure \\
\hline 4.50 & Esterification & $-\stackrel{\mathrm{C}}{\mathrm{C}}-\mathrm{O}-\mathrm{C}-\mathrm{O}-\mathrm{CH}_{2} * \mathrm{CH}_{2}-\mathrm{O}-\stackrel{\|}{\mathrm{C}}\left(\mathrm{CH}_{2}\right)_{5} \mathrm{O}-$ \\
\hline 4.40 & Esterification & $-\stackrel{\mathrm{O}}{\mathrm{C}}-\stackrel{\mathrm{O}}{\mathrm{II}}-\mathrm{O}-\mathrm{CH}_{2} \mathrm{CH}_{2} *-\mathrm{O}-\stackrel{\mathrm{O}}{\mathrm{C}}\left(\mathrm{CH}_{2}\right)_{5} \mathrm{O}-$ \\
\hline 4.25 & Transesterification & $\stackrel{\mathrm{O}}{\|} \stackrel{\mathrm{C}}{\mathrm{C}}-\mathrm{OCH}_{2} *\left(\mathrm{CH}_{2}\right)_{4} \mathrm{C}-$ \\
\hline 4.20 & Transesterification & $\stackrel{\mathrm{O}}{\stackrel{\mathrm{O}}{\|}\left(\mathrm{CH}_{2}\right)_{5}-\mathrm{C}-\mathrm{O}-\mathrm{CH}_{2} * \mathrm{CH}_{2} *-\mathrm{O}-\stackrel{\mathrm{O}}{\mathrm{C}}\left(\mathrm{CH}_{2}\right)_{5} \mathrm{O}-}$ \\
\hline
\end{tabular}

This percentage has been calculated for each experiment (Table 1) and a correlation between the esterester interchange reaction and the thermal behaviour of the copolyesters has been investigated.

When the copolyesters are synthesized from PCL of $\bar{M}_{\mathrm{n}}=730 \mathrm{~g} \cdot \mathrm{mol}^{-1}$, the non-catalyzed reaction gave polyester with about $8 \%$ of transesterification reaction, and the ester-ester interchange reaction with titanium-catalyzed copolyester is quantified at about $15 \%$. The results show a link between titanium and ester-ester interchange reaction. It can be a remark also, that the exchange percentage of ester-ester is higher for the copolyester $\mathbf{1}(35 \%)$. This is probably due to the low reactivity of PCL used with higher molecular weight. Therefore, the low amount of ester-ester interchange reaction in the copolyester $\underline{\mathbf{2}}$ is clear and it can be attributed to the utilization of PCL with low molecular weight.

The DSC thermogram shows that the copolyester $\underline{1}$ does not present a crystalline phase and has only one glass transition temperature $\left(T_{\mathrm{g}}\right)$, comprised between the $T_{\mathrm{g}}$ of the PET oligomers and the PCL. The intermediate $T_{\mathrm{g}}$ shows that this copolyester does not present phase segregation phenomenon. It can be explained by the ester-ester interchange reaction. This reaction prevents the copolyester from having thermoplastic elastomer behaviour because length of soft and hard segments decreases and phase segregation is then defavorized.

The immiscibility of PET and PCL was shown by Ma and Prud'homme [46]. However, in our case, the obtained DSC analysis showed that this polyester is constituted by only one phase. This can be linked to the secondary reaction, occurring during polyesterification, which leads to a homogenous mixture.
The use of the Fox-Flory law for blends of miscible polymers could be interesting in order to verify the miscibility of the two phases present in the copolyester $\underline{1}$. If the glass transition temperature of the copolyester, determined by DSC analysis, is close to the calculated one, the hypothesis of non-phase segregation is confirmed. The Fox-Flory equation (Equation (4)) gives the theoretical value of glass transition temperature of $-24^{\circ} \mathrm{C}$ for this copolyester:

$\frac{1}{T_{\mathrm{g}}}=\sum \frac{\omega_{\mathrm{i}}}{T_{\mathrm{gi}}}$

where $\omega_{\mathrm{i}}$ is the fraction weight of polymer $i$ in the blend and $T_{\mathrm{g}} \mathrm{i}$ the glass transition temperature of the polymer $i$.

The comparison between this value and the experimental value obtained by DSC analysis (Table 1) shows that this co-polyester approaches a mono phase compound behaviour. It can be linked with the ester-ester exchange reaction that produces random co-polyester in which phase segregation phenomenon cannot occur.

The co-polyesters $\underline{\mathbf{2}}$ and $\underline{\mathbf{3}}$ present only one glass transition temperature (about $-6^{\circ} \mathrm{C}$ with non-catalyzed reaction and $-10^{\circ} \mathrm{C}$ with titanium catalyzed reaction) and only one melting point $\left(T_{\mathrm{m}}\right)$ ranging between 200 and $208^{\circ} \mathrm{C}$ (Table 1). However no crystallization temperature $\left(T_{\mathrm{c}}\right)$ can be observed. These obtained co-polyesters are phase segregated. They present amorphous and crystalline phases. The $T_{\mathrm{g}}$ of each co-polyester was different if compared to the theoretical one, calculated using the Fox-Flory law, and which confirms the coexistence of crystalline and amorphous phases in these co-poly- 
esters. Thus, it proves the immiscibility of the two phases. Therefore, it seems that when the ester-ester exchange reaction ratio is not high, the trans-esterification reactions do not prevent the co-polyester from being a segregated product.

The decreasing of the co-polyesters $T_{\mathrm{m}}$ shows also an evolution in the phase segregation. This phenomenon could be explained by the coexistence of a crystalline phase with a high content of PET and a low content of PCL, and an amorphous phase with a high content of PCL and a low amount of PET. The decreasing of PET amount in the crystalline phase can be explained by the loss of the crystallizing point. However $T_{\mathrm{m}}$ and $T_{\mathrm{c}}$ of the PCL have not been detected in the crystalline phase. This hypothesis is in accordance with the work of Ma and Prud'homme [46] which showed the immiscibility of PET and PCL.

\section{Conclusions}

In the present work, PET is depolymerized by its BHET monomer. Hydroxytelechelic oligomers were obtained in good yield with a molecular weight of $\bar{M}_{\mathrm{n}}=1360 \mathrm{~g} \cdot \mathrm{mol}^{-1}$. The thermal properties of the obtained oligomers were found comparable to the properties of the starting PET.

Further, the synthesis of co-polyesters was achieved by polyesterification of the reactive $\alpha-\omega$, hydroxy oligomers of the PET and $\alpha-\omega$, carboxy PCL. The chemical structure of the synthesized co-polyesters was established by SEC and ${ }^{1} \mathrm{H}$ NMR spectroscopy. The comparison of the molecular weights of the obtained co-polyesters showed that the catalyst enhances the molecular weight of the obtained copolyesters, and the use of carboxytelechelic PCL oligomers with high molecular weight $\left(\bar{M}_{\mathrm{n}}=\right.$ $2300 \mathrm{~g} \cdot \mathrm{mol}^{-1}$ ) gives a co-polyester with a lower molecular weight. This may be due to the low reactivity of the terminal carboxylic functions.

Furthermore, the presence of the titanium catalyst improves both the polyesterification and the esterester exchange reaction. This phenomenon also affects the thermoplastic properties of the obtained co-polyesters. The phase segregation is limited at high ester-ester exchange reaction ratio. However, when the ester-ester exchange reaction ratio is not high, the trans-esterification reactions do not prevent the co-polyester from being a segregated product. The phase segregation permits, in this case, to obtain a thermoplastic elastomer compound. This may be achieved using oligomers carboxytelechelic PCL with a lower $\bar{M}_{\mathrm{n}}$ (e.g. $\bar{M}_{\mathrm{n}}=730$ g.mol-1).

\section{Acknowledgements}

The authors gratefully thank the CNRST (Morocco) and the program Morocco-Tunisian (project code: 13/MT/24) for their financial support of this work.

\section{References}

[1] Karayannidis G. P., Nikolaidis A. K., Sideridou I. D., Bikiaris D. N., Achilias D. S.: Chemical recycling of PET by glycolysis: Polymerization and characterization of the dimethacrylated glycolysate. Macromolecular Materials and Engineering, 291, 1338-1347 (2006). DOI: $10.1002 /$ mame. 200600243

[2] Smithers Pira organization. The Future of Global PET Packaging to 2017. Pira International Market Report Organization (2012).

[3] Siddiqui M. N., Redhwi H. H., Achilias D. S.: Recycling of poly(ethylene terephthalate) waste through methanolic pyrolysis in a microwave reactor. Journal of Analytical and Applied Pyrolysis, 98, 214-220 (2012). DOI: 10.1016/j.jaap.2012.09.007

[4] Navarro R., Ferràndiz S., López J, Seguí V. J.: The influence of polyethylene in the mechanical recycling of polyethylene terephtalate. Journal of Materials Processing Technology, 195, 110-116 (2008).

DOI: 10.1016/j.jmatprotec.2007.04.126

[5] Awaja F., Pavel D.: Recycling of PET. European Polymer Journal, 41, 1453-1477 (2005). DOI: 10.1016/j.eurpolymj.2005.02.005

[6] Beneš H., Slabá J., Walterová Z., Rais D.: Recycling of waste poly(ethylene terephthalate) with castor oil using microwave heating. Polymer Degradation and Stability, 98, 2232-2243 (2013).

DOI: $10.1016 /$ j.polymdegradstab.2013.08.019

[7] Tawfik M. E., Eskander S. B.: Chemical recycling of poly(ethylene terephthalate) waste using ethanolamine. Sorting of the end products. Polymer Degradation and Stability, 95, 187-194 (2010).

DOI: $10.1016 /$ j.polymdegradstab.2009.11.026

[8] Güçlü G., Yalçınyuva T., Özgümüş S., Orbay M.: Simultaneous glycolysis and hydrolysis of polyethylene terephthalate and characterization of products by differential scanning calorimetry. Polymer, 44, 76097616 (2003).

DOI: $10.1016 /$ j.polymer.2003.09.062

[9] Karayannidis G. P., Achilias D. S.: Chemical recycling of poly(ethylene terephthalate). Macromolecular Materials and Engineering, 292, 128-146 (2007).

DOI: $10.1002 /$ mame. 200600341

[10] Shukla S. R., Harad A. M., Jawale L. S.: Chemical recycling of PET waste into hydrophobic textile dyestuffs. Polymer Degradation and Stability, 94, 604609 (2009).

DOI: $10.1016 /$ j.polymdegradstab.2009.01.007 
[11] Nikles D. E., Farahat M. S.: New motivation for the depolymerization products derived from poly(ethylene terephthalate) (PET) waste: A review. Macromolecular Materials and Engineering, 290, 13-30 (2005).

DOI: $10.1002 /$ mame. 200400186

[12] Ghaemy M., Behzadi F.: Unsaturated polyester from glycolized PET recycled from post-consumer softdrink bottles. Iranian Polymer Journal, 11, 77-83 (2002).

[13] Roy P. K., Mathur R., Kumar D., Rajagopal C.: Tertiary recycling of poly(ethylene terephthalate) wastes for production of polyurethane-polyisocyanurate foams. Journal of Environmental Chemical Engineering, 1, 1062-1069 (2013).

DOI: $10.1016 /$ j.jece.2013.08.019

[14] Kathalewar M., Dhopatkar N., Pacharane B., Sabnis A., Raut P., Bhave V.: Chemical recycling of PET using neopentyl glycol: Reaction kinetics and preparation of polyurethane coatings. Progress in Organic Coatings, 76, 147-156 (2013).

DOI: $10.1016 /$ j.porgcoat.2012.08.023

[15] Patel M. R., Patel J. V., Sinha V. K.: Polymeric precursors from PET waste and their application in polyurethane coatings. Polymer Degradation and Stability, 90, 111-115 (2005).

DOI: $10.1016 /$ j.polymdegradstab.2005.02.017

[16] Auvergne R., Saint-Loup R., Joly-Duhamel C., Robin J. J., Boutevin B.: UV curing of a novel resin derived from poly(ethylene terephthalate). Journal of Polymer Science Part A: Polymer Chemistry, 45, 1324-1335 (2007).

DOI: $10.1002 /$ pola.21904

[17] Patel M. R., Patel J. V., Sinha V. K.: Glycolyzed PET waste and castor oil-based polyols for two-pack coating systems. Polymer International, 55, 1315-1322 (2006). DOI: $10.1002 /$ pi.2086

[18] Atta A. M., Elnagdy S. I., Manar E. A-R., Elsaeed S. M., Abdel-Azim A-A. A.: Compressive properties and curing behaviour of unsaturated polyester resins in the presence of vinyl ester resins derived from recycled poly (ethylene terephthalate). Journal of Polymer Research, 12, 373-383 (2005).

DOI: $10.1007 / \mathrm{s} 10965-005-1638-3$

[19] Karayannidis G. P., Achilias D. S., Sideridou I. D., Bikiaris D. N.: Alkyd resins derived from glycolized waste poly(ethylene terephthalate). European Polymer Journal, 41, 201-210 (2005).

DOI: $10.1016 /$ j.eurpolymj.2004.10.001

[20] Al-Salem S. M., Lettieri P., Baeyens J.: Recycling and recovery routes of plastic solid waste (PSW): A review. Waste Management, 29, 2625-2643 (2009). DOI: 10.1016/j.wasman.2009.06.004

[21] Dehghani A., Ardekani S. M., Al-Maadeed M. A., Hassan A., Wahit M. U.: Mechanical and thermal properties of date palm leaf fiber reinforced recycled poly (ethylene terephthalate) composites. Materials and Design, 5, 841-848 (2013).

DOI: $10.1016 /$ j.matdes.2013.06.022
[22] Shukla S. R., Harad A. M., Jawale L. S.: Recycling of waste PET into useful textile auxiliaries. Waste Management, 28, 51-56 (2008).

DOI: 10.1016/J.WASMAN.2006.11.002

[23] Viana M. E., Riul A., Carvalho G. M., Rubira A. F., Muniz E. C.: Chemical recycling of PET by catalyzed glycolysis: Kinetics of the heterogeneous reaction. Chemical Engineering Journal, 173, 210-219 (2011). DOI: $10.1016 /$ j.cej.2011.07.031

[24] Imran M., Kim D. H., Al-Masry W. A., Mahmood A., Hassan A., Haider S., Ramay S. M.: Manganese-, cobalt-, and zinc-based mixed-oxide spinels as novel catalysts for the chemical recycling of poly(ethylene terephthalate) via glycolysis. Polymer Degradation and Stability, 98, 904-915 (2013).

DOI: 10.1016/j.polymdegradstab.2013.01.007

[25] López-Fonseca R., Duque-Ingunza I., De Rivas B., Arnaiz S., Gutiérrez-Ortiz J. I.: Chemical recycling of post-consumer PET wastes by glycolysis in the presence of metal salts. Polymer Degradation and Stability, 95, 1022-1028 (2010). DOI: $10.1016 /$ j.polymdegradstab.2010.03.007

[26] Wang H., Liu Y., Li Z., Zhang X., Zhang S., Zhang Y.: Glycolysis of poly(ethylene terephthalate) catalyzed by ionic liquids. European Polymer Journal, 45, 15351544 (2009).

DOI: $10.1016 / j$.eurpolymj.2009.01.025

[27] Pardal F., Tersac G.: Kinetics of poly(ethylene terephthalate) glycolysis by diethylene glycol. I. Evolution of liquid and solid phases. Polymer Degradation and Stability, 91, 2840-2847 (2006).

DOI: $10.1016 /$ j.polymdegradstab.2006.09.009

[28] Baliga S., Wong W. T.: Depolymerization of poly(ethylene terephthalate) recycled from post-consumer soft-drink bottles. Journal of Polymer Science Part A: Polymer Chemistry, 27, 2071-2082 (1989).

DOI: $10.1002 /$ pola.1989.080270625

[29] Ikladious N. E.: Recycling of poly(ethylene terephthalate): Identification of glycolysis products. Journal of Elastomers and Plastics, 32, 140-151 (2000). DOI: $10.1177 / 009524430003200203$

[30] Mansour S. H., Ikladious N. E.: Depolymerization of poly(ethylene terephthalate) wastes using 1,4-butanediol and triethylene glycol. Polymer Testing, 21, 497-505 (2002).

DOI: 10.1016/S0142-9418(01)00115-5

[31] Mansour S. H., Abd-El-Messieh S. L., Ikladious N. E.: Utilization of some oligomers based on poly(ethylene terephthalate) wastes as modifiers for polyvinyl chloride. Journal of Applied Polymer Science, 85, 25012509 (2002).

DOI: 10.1002/app.10608

[32] Colomines G., Robin J-J., Tersac G.: Study of the glycolysis of PET by oligoesters. Polymer, 46, 32303247 (2005).

DOI: $10.1016 /$ j.polymer.2005.02.047 
[33] Colomines G., Rivas F., Lacoste M-L., Robin J-J.: Study of polyurethane formulations containing diols obtained via glycolysis of poly(ethylene terephthalate) (PET) by oligoesters diols through a reactive extrusion process. Macromolecular Materials and Engineering, 290, 710-720 (2005).

DOI: $10.1002 /$ mame.200400391

[34] Zahedi A. R., Rafizadeh M., Ghafarian S. R.: Unsaturated polyester resin via chemical recycling of off-grade poly(ethylene terephthalate). Polymer International, 58, 1084-1091 (2009).

DOI: $10.1002 /$ pi.2637

[35] Saint-Loup R., Robin J-J., Boutevin B.: Synthesis of poly(ethylene terephthalate)-block-poly(tetramethylene oxide) copolymer by direct polyesterification of reactive oligomers. Macromolecular Chemistry and Physics, 204, 970-982 (2003).

DOI: $10.1002 /$ macp. 200390072

[36] Michel A., Cassagnau P., Argalon D. M., Robin J. J.: Synthesis of diols by the alcoholysis of molten polyesters with a diol or ether-diol in the presence of a catalyst, useful for the chemical vaporization of thermoplastic waste material particularly terephthalates. Fr Patent 2825701-A1, France (2001).

[37] Lusinchi J. M., Pietrasanta Y., Robin J. J., Boutevin B.: Recycling of PET and PVC wastes. Journal of Applied Polymer Science, 69, 657-665 (1998).

DOI: $10.1002 /($ SICI) 1097-4628(19980725)69:4<657:: AID-APP4>3.0.CO;2-I

[38] Ma D., Zhang G., Huang Z., Luo X.: Synthesis and chain structure of ethylene terephthalate- $\varepsilon$-caprolactone copolyesters. Journal of Polymer Science Part A: Polymer Chemistry, 36, 2961-2969 (1998).

DOI: $10.1002 /($ SICI)1099-0518(19981130)36:16<2961 $\because$ AID-POLA14>3.0.CO;2-T

[39] Laurienzo P., Immirzi B., Malinconico M.: A preliminary investigation on the use of poly[(ethylene terephthalate)-co-( $\varepsilon$-caprolactone)] copolymer as compatibiliser of HDPE/PET blends. Macromolecular Materials and Engineering, 286, 248-253 (2001). DOI: $10.1002 / 1439-2054(20010401) 286: 4<248:: A I D-$ MAME248>3.0.CO;2-9
[40] Pesneau I., Grégoire M., Michel A.: Catalytic aspect of chemical modifications of polymers by transesterification: NMR study with model compounds. Journal of Applied Polymer Science, 79, 1556-1562 (2000).

DOI: $10.1002 / 1097-4628(20010228) 79: 9<1556:: A I D-$ APP30>3.0.CO;2-F

[41] Maafi E. M., Malek F., Tighzert L., Laoutid F., Dubois P.: Synthesis and thermal properties of new copolyesters based on polycaprolactone. e-Polymers, no.027 (2012). DOI: $10.1515 /$ epoly.2012.12.1.304

[42] Siling M. I., Laricheva T. N.: Titanium compounds as catalysts for esterification and transesterification. Russian Chemical Reviews, 65, 279-286 (1996). DOI: 10.1070/RC1996v065n03ABEH000210

[43] Fradet A., Marechal E.: Models for polyesterification kinetics. II. Esterification kinetics in nonpolar medium. Journal of Macromolecular Science Part A: Chemistry, 17, 859-879 (1982).

DOI: $10.1080 / 00222338208063277$

[44] Seebach D., Hungerbühler E., Naef R., Schnurrenberger P., Weidmann B., Züger M.: Titanate-mediated transesterifications with functionalized substrates. Synthesis, 1982, 138-141 (1982).

DOI: $10.1055 / \mathrm{s}-1982-29718$

[45] Park S. S., Chae S. H., Im S. S.: Transesterification and crystallization behavior of poly(butylene succinate)/poly(butylene terephthalate) block copolymers. Journal of Polymer Science Part A: Polymer Chemistry, 36, 147-156 (1998).

DOI: 10.1002/(SICI)1099-0518(19980115)36:1<147::

$$
\text { AID-POLA19>3.0.CO;2-J }
$$

[46] Ma D-Z, Prud'homme R. E.: Miscibility of caprolactone/ethylene terephthalate copolymers with chlorinated polymers: A differential scanning calorimetry and Fourier transform infra-red study. Polymer, 31, 917-923 (1990).

DOI: 10.1016/0032-3861(90)90056-5

[47] Wei K-H., Ho J-C.: The role of transesterification on the miscibility in blends of polycarbonate and liquid crystalline copolyester. Macromolecules, 30, 15871593 (1997).

DOI: $\underline{10.1021 / \operatorname{ma9} 615260}$ 